CARBON 79 (2014) 432-441

http://dx.doi.org/10.1016/j.carbon.2014.08.0012014.08.022

\title{
Visible Light Driven Photoelectrochemical Water Splitting on Metal \\ Free Nanoporous Carbon Promoted by Chromophoric Functional \\ Groups
}

Conchi O. Ania, ${ }^{\mathrm{a}}$ Mykola Seredych, ${ }^{\mathrm{b}}$ Enrique Rodríguez-Castellón, ${ }^{\mathrm{c}}$ and Teresa J. Bandosz ${ }^{\mathrm{b}^{*}}$

${ }^{a}$ Department of Chemical Processes in Energy and Environment, Instituto Nacional del Carbón (INCAR, CSIC), C/ Francisco Pintado Fe 26, Oviedo 33011, Spain

${ }^{\mathrm{b}}$ Department of Chemistry and CUNY Energy Institute, The City College of New York, 160 Convent Ave, New York, NY 10031, United States

${ }^{c}$ Departamento de Química Inorgánica, Facultad de Ciencias, Universidad de Málaga, 29071 Málaga, Spain

${ }^{*}$ Corresponding author. Tel: +1 212650 6017; Fax: +1 212650 6107. E-mail address: tbandosz@ccny.cuny.edu (T.J. Bandosz) 


\begin{abstract}
A nanoporous carbon was prepared from sulfonic acid based water soluble polymer. Its direct one step carbonization followed by air oxidation led to a porous material whose surface was rich in $\mathrm{N}-$, O- and S- containing groups. TEM images showed the presence of $10 \mathrm{~nm}$ graphitic domains in the carbon matrix. When the carbon was used as a photoanode under visible light irradiation, oxygen evolution occurred at overpotentials as low as $+0.8 \mathrm{~V}$ vs. $\mathrm{Ag} / \mathrm{AgCl}$. The ability of the carbon to oxidize water was linked to the presence of sulfur and nitrogen containing groups working as chromophores whose electrons are excited by irradiation leaving reactive vacancies (holes) that are able to accept electrons from oxygen in water molecules. The conductivity of the carbon matrix and the presence of small pores were found of paramount importance. While the former helps in electron transfer within the carbon matrix, strong adsorption of water molecules in micropores close to chromophores enhances the electron transfer from oxygen to the vacancy on the chromophore promoting water splitting and oxygen evolution. This work provides the first direct experimental evidence of water photooxidation reactions using metal-free nanoporous carbons exposed to visible light.
\end{abstract}




\section{Introduction}

Light irradiation has become an explored method to split water using either photoelectrochemical (PEC) or catalytic methods. Catalytic water splitting (WS) on semiconducting materials involves photoinduced electron-hole pairs and the phase transfer reactions of the charge carriers to generate $\mathrm{O}_{2}$ and $\mathrm{H}_{2}$. An efficient WS catalyst should have appropriate band gap structure, high density of active sites, and fast charge separation. Besides semiconducting metal oxides and salts [1-3], graphene, CNT and graphite oxide have recently gained a considerable attention [4-12]. The visible light (VL) activity of nanostructured carbon materials (nonporous) has been reported and linked to the high electron mobility on the graphene units [4-6], and the surface functionalization, where specific functional groups undergo light excitation [5], enhancing the efficiency of electron injection to the conduction band of a photocatalyst in a multiphase system. Recently it has been shown that functionalized nanoporous carbons able to generate photocurrent under visible light irradiation $[13,14]$. This photoactivity was found as an important feature for oxidation of dibenzothiophenes [15], electrical energy storage in supercapacitors [16], and in oxidation of water pollutants [17]. Moreover, nanoporous carbon photoluminescence was linked to the presence of heteroatom, which in specific configurations can act as fluorophores reemitting light upon excitation [18].

Following the applications of carbon materials in photoassisted reactions, for the first time we show the PEC water splitting on a metal-free nanoporous carbon photoanode under VL. Compared to other studies on metal-free carbon photoanodes $[7,8]$, our material is a low cost electrode obtained from a commodity organic polymer. Based on an extensive surface characterization, an attempt is made to link the photoelectrochemical water splitting ability of the studied carbon to its rich surface chemistry (via O, S and N-doping) and specific textural and 
structural features.

\section{Experimental}

\subsection{Materials}

The polymer-derived carbon was obtained from poly(4-ammonium styrene-sulfonic acid) polymer by carbonization at $800{ }^{\circ} \mathrm{C}$ for $40 \mathrm{~min}\left(\mathrm{~N}_{2}\right.$ flow rate of $300 \mathrm{~mL} / \mathrm{min}$ and heating rate of $50{ }^{\circ} \mathrm{C} / \mathrm{min}$ ) followed by air oxidation at $350{ }^{\circ} \mathrm{C}$ for 3 hours. The initial material is referred to as CONS-I, and that after cycling as CONS-E. The formula of the organic polymer used as precursor for the preparation of the nanoporous carbon material is presented in Figure 1. In its chemical structure sulfur and nitrogen are present. They are expected to undergo complex transformations during carbonization leading to the new functionalities, including their incorporation to aromatic rings [19]. Even though the properties of this carbon have been addressed in details in Ref. [18] where the photoluminescence effect was discussed, for the clarity of the data analysis we reintroduce some important textural and chemical properties to explain the observed phenomena.

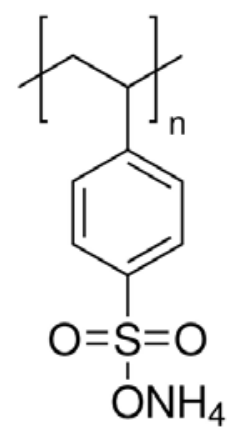

Figure 1. Chemical formula of the carbon precursor poly(4-ammonium styrene-sulfonic acid) polymer. 
To clearly indicate the importance of specific surface features on the photoelectrochemical activity upon visible light irradiation, we also tested the carbon prepared by carbonization of the polymer before air oxidation (sample referred to as CONS) and a commercial wood-based activated carbon, BAX (BAX-1500, Mead Westvaco).

\subsection{Methods}

2.2.1. Photoelectrochemical measurements: A standard three-compartment cell was used, consisting of the nanoporous carbon photoanode as a working electrode, a Pt wire counter electrode, and a saturated $\mathrm{Ag} / \mathrm{AgCl}$ reference electrode. For the preparation of the photoanodes a slurry of the nanoporous carbon, PVDF and a carbon black conductive additive (ratio 85:10:5) in $\mathrm{N}$-methyl-2-pyrrolidone was coated on a $1 \mathrm{~cm}^{2} \mathrm{Ti}$ foil collector. The electrodes were dried in air at $120{ }^{\circ} \mathrm{C}$ before usage. A solar simulator (irradiation density of $75 \mathrm{~W} / \mathrm{cm}^{2}$, Solar Light Co., INC, XPS- $150^{\mathrm{TM}}$ ) was used as irradiation source; a pyrex filter (cut-off below $420 \mathrm{~nm}$ ) was used to isolate the contribution of visible light in the solar simulator. A VersaSTAT MC (Princeton Applied Research) workstation was used to evaluate the electrochemical behavior. The transient of photocurrent was obtained under a constant bias potential between 0 and $+1.5 \mathrm{~V}$ vs. $\mathrm{Ag} / \mathrm{AgCl}$ under on/off illumination. Dark current equilibrium at the applied potential was allowed before the irradiation. The photoanodes were suspended in $50 \mathrm{~mL}$ of an aqueous solution of $0.1 \mathrm{M}$ $\mathrm{Na}_{2} \mathrm{SO}_{4}$ ( $\mathrm{pH}$ was adjusted to 2 ) and purged with $\mathrm{N}_{2}$ for 1 hour before the illumination. The electrochemical behavior of the electrodes was also explored by applying a linear potential sweep at a scan rate of $20 \mathrm{mV} / \mathrm{s}$, before and after light exposure. 
Potentiostatic electrochemical impedance spectroscopy (EIS) measurements were performed in the frequency range of $1 \mathrm{mHz}-100 \mathrm{kHz}$ with a $10 \mathrm{mV}$ AC amplitude for the best performing carbon, CONS-I, before and after water splitting.

2.2.2. Oxygen measurements: The $\mathrm{O}_{2}$ concentration was measured in the electrochemical cell using an oxygen sensor (LDO101 HACH Company, Model - HQ440d) immersed in the electrolyte. The sensor was calibrated with a two-point calibration technique, following the procedure suggested by the manufacturer. The ambient $\mathrm{O}_{2}(\mathrm{~g})$ leak rate into the cell was established by analyzing the oxygen content before the irradiation during the periods at opencircuit and dark conditions, and subtracting it from the total response. The Faradaic oxygen production efficiency, $\eta_{2}$, for the oxygen evolved from water oxidation was calculated by comparing the amount of oxygen output detected in the PEC experiments and the calculated theoretical amount of oxygen produced based on the total charge passed assuming $100 \% \mathrm{O}_{2}$ yield and using the Faraday's law of electrolysis $n=Q / z F$, where $n$ is the number of mole, $\mathrm{Q}$ is the charge passed during electrolysis, $\mathrm{F}$ is faraday's constant which equal to $96,485 \mathrm{C} / \mathrm{mol}$ and $\mathrm{z}=4$ is the number of electrons involved in OER.

2.2.3. Surface characterization techniques: X-ray diffraction (XRD) measurements were conducted using $\mathrm{CuK}_{\alpha}$ radiation $(40 \mathrm{kV}, 40 \mathrm{~mA})$ generated in a Phillips X'Pert apparatus. Scanning electron microscopy (SEM) images were obtained at a Zeiss Supra 55 VP operating at $5 \mathrm{kV}$. High-resolution transmission electron microscopy (HR-TEM) was performed on a JEOL 2100 LaB6 instrument operating at 200 kV. X-Ray Photoelectron Spectroscopy measurements were performed on a Physical Electronics PHI 5700 spectrometer with nonmonochromatic $\mathrm{Mg}_{\mathrm{K} \alpha}$ radiation $(300 \mathrm{~W}, 15 \mathrm{kV}, 1253.6 \mathrm{eV})$. Raman spectra were obtained on a Princeton apparatus using a $514.5 \mathrm{~nm}$ Argon-ion laser. Sorption of nitrogen at its boiling point was carried out using 
ASAP 2020 (Micromeritics, Surface Area and Porosity Analyzer). Before the experiments, samples were out-gassed at $120{ }^{\circ} \mathrm{C}$ to constant vacuum $\left(10^{-4}\right.$ Torr). The surface areas (BET method), total pore volumes, $\mathrm{V}_{\mathrm{t}}$, (from the last point of isotherm at relative pressure equal to 0.99), volumes of micropores, volume in pores less than $1 \mathrm{~nm}$, mesopore volumes along with pore size distributions were calculated from the isotherms. The last four quantities were calculated using Density Functional Theory, DFT [20, 21].

2.2.4. Thermal analysis-mass spectrometry (TA-MS): Thermogravimetric (TG) curves were obtained using a TA instrument thermal analyzer (SDT Q 600), which was connected to a gas analysis system (OMNI Star ${ }^{\mathrm{TM}}$ ) mass spectrometer. The carbon sample was heated up to $1000{ }^{\circ} \mathrm{C}$ $\left(10{ }^{\circ} \mathrm{C} / \mathrm{min}\right)$ under a constant helium flow $(100 \mathrm{~mL} / \mathrm{min})$. From the TG curves, differential TG (DTG) curves were derived. The composition of gases was evaluated by MS and gas evolution profiles as a function of temperature were obtained.

2.2.5. Water affinity evaluation: The changes in surface hydrophilicity were determined by measuring water adsorption affinity. The initial carbon sample mixed with the binder and carbon black (of the same proportions as those used to prepare electrodes) and the recovered sample after the electrochemical testing were dried at $120{ }^{\circ} \mathrm{C}$ to constant mass and placed in a closes vessel with constant pressure of water vapor at ambient temperature. After 24 hours the TA experiments were carried out using a TA instrument thermal analyzer (SDT Q 600). The weigh lost in nitrogen between 30 and $120{ }^{\circ} \mathrm{C}$ was assumed as an equivalent to the quantity of water adsorbed on the surface.

2.2.6. DC conductivity measurements: The DC conductivity was measured using a 4-probe method on the pellets with the composition 90 wt. \% of carbon materials and 10 wt. \% polytetrafluoroethylene as binder. The prepared composition was pressed by a Carver Press 
machine applying 2 tons pressure and a disk-shaped well-packed pellets with diameter $8 \mathrm{~mm}$ were formed. The pellets were dried in oven for 12 hours. The pellets' thickness was measured by a spring micrometer. The measurement of conductivity was carried out using the Keithley 2400 multimeter.

\section{Results and Discussion}

Figure 2a shows the comparison of the photocurrent generation at different bias potential on the three carbons tested. Data corresponding to the bare titanium foil used as a current collector is also included for comparison. As seen, a remarkable photocurrent was generated when the electrode was polarized at sufficiently high anodic potentials. Furthermore, the potential onset of the photocurrent is $+0.8 \mathrm{~V}$ for the carbon anodes, clearly lower than the value for the $\mathrm{Ti}$ collector. Current densities up to $0.45 \mathrm{~mA} / \mathrm{cm}^{2}$ were recorded for the highest potentials. Even though they are not so high as those reported for other water splitting photocatalysts, they are most outstanding for a metal-free nanoporous carbon photoanode. The best performing carbon is CONS-I and in further discussion the focus of the analysis will be on this particular material.

Figure $2 \mathrm{~b}$ shows the transient photocurrent response of the photoanode made of CONS-I after on/off illumination at $+0.8 \mathrm{~V}$. The generation of $\mathrm{O}_{2}$ gas was confirmed by direct measurement of its concentrations in water (Figure 2a). Moreover, the extensive bubbling seen on the electrode upon illumination was not seen in dark, or during irradiation of the Ti collector and binder, confirming the VL activity of the anode for the oxygen evolution reaction (OER). 
a)

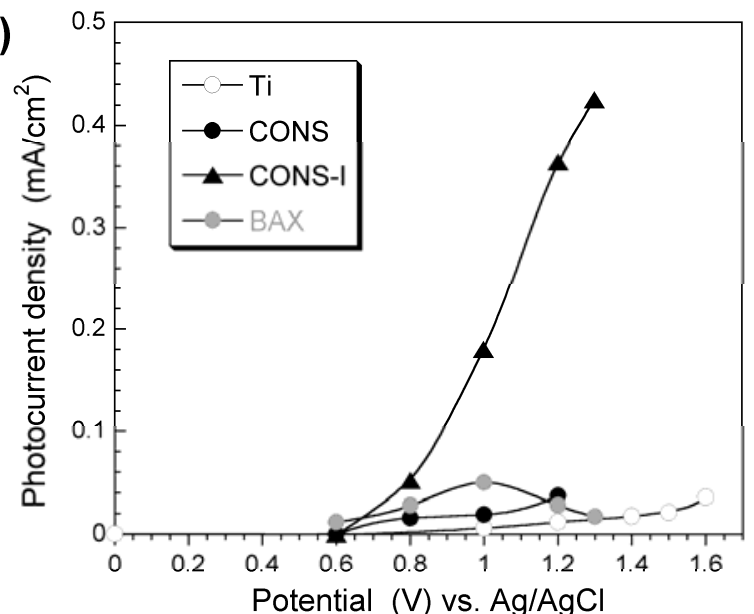

b)

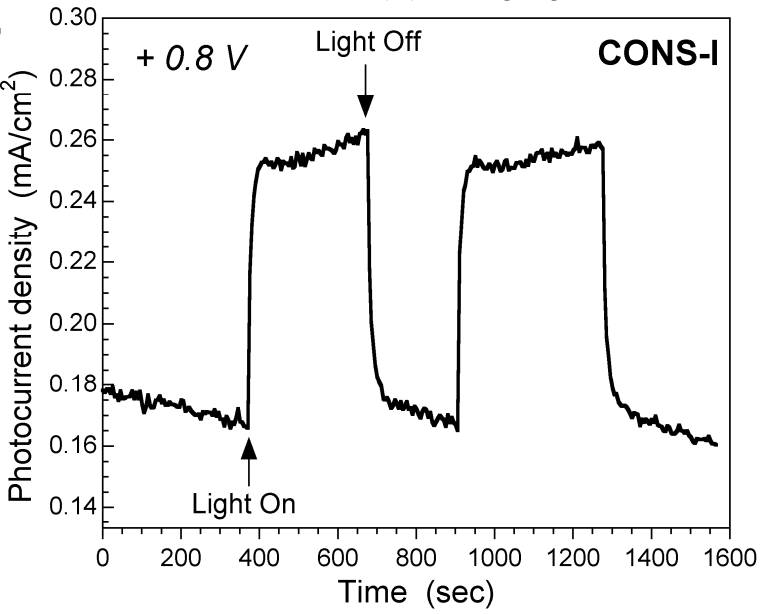

c)

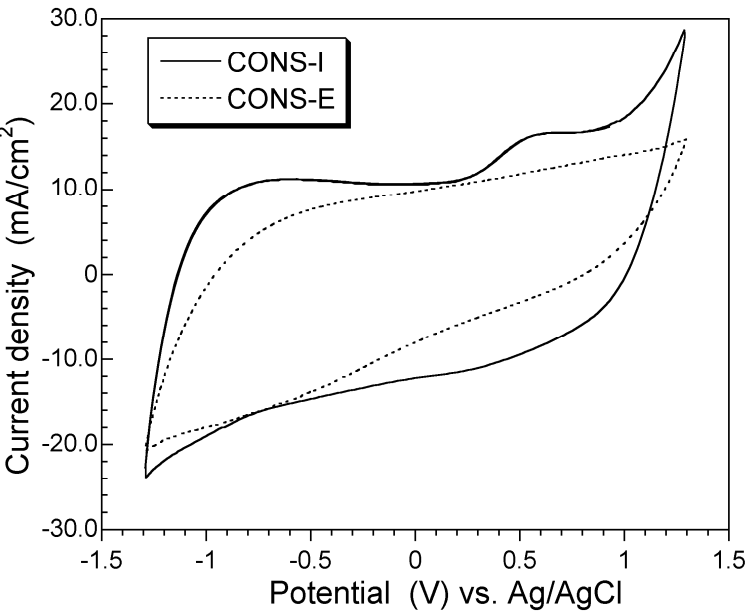

Figure 2. (a) photocurrent vs bias potential of the photoanodes; (b) chronoamperometric response of sample CONS-I upon on/off illumination at $0.8 \mathrm{~V} \mathrm{vs} \mathrm{Ag} / \mathrm{AgCl}$; c) $\mathrm{CV}$ curves before and after VL exposure. 
The generation of the photocurrent was stable and reproducible after several illumination cycles and upon several hours of illumination (Figure 3b). Furthermore, the amount of $\mathrm{O}_{2}$ detected after 3 hours of illumination at $0.8 \mathrm{~V}$ (the lowest applied potential), was consistent with the value estimated from the accumulated charge passed, thus indicating a Faradaic efficiency close to 100 $\%$. However, the efficiency was rather small at short illumination periods, following an increasing pattern upon time, suggesting that charge is also consumed in side reactions. Indeed, some changes become evident in the cyclic voltammogram (CV) of the carbon electrode after illumination (Figure 2c), suggesting a photo- or electro-corrosion of the anode. The CV of the asprepared electrode is typical for a nanoporous carbon with the electrical double layer capacitance (EDLC) [22], and a wide hump centered at $0.6 \mathrm{~V}$, linked to the redox reactions of $\mathrm{O}, \mathrm{N}$, and $\mathrm{S}$ surface groups in various environments [23]. This hump disappears after exposure to VL at high potentials indicating surface photosensitivity in the water splitting process or suggesting that some specific sites of the carbon electrode might consume the photogenerated charges [24]. After VL exposure, the CV loses its rectangular shape, indicating charge transfer limitations. A broad hump appears on the cathodic sweep between -0.5 and $-0.8 \mathrm{~V}$ after irradiation under anodic polarization. This suggests an irreversible change in carbon surface chemistry indicating that thus chemistry is the major feature responsible for the PEC activity. 

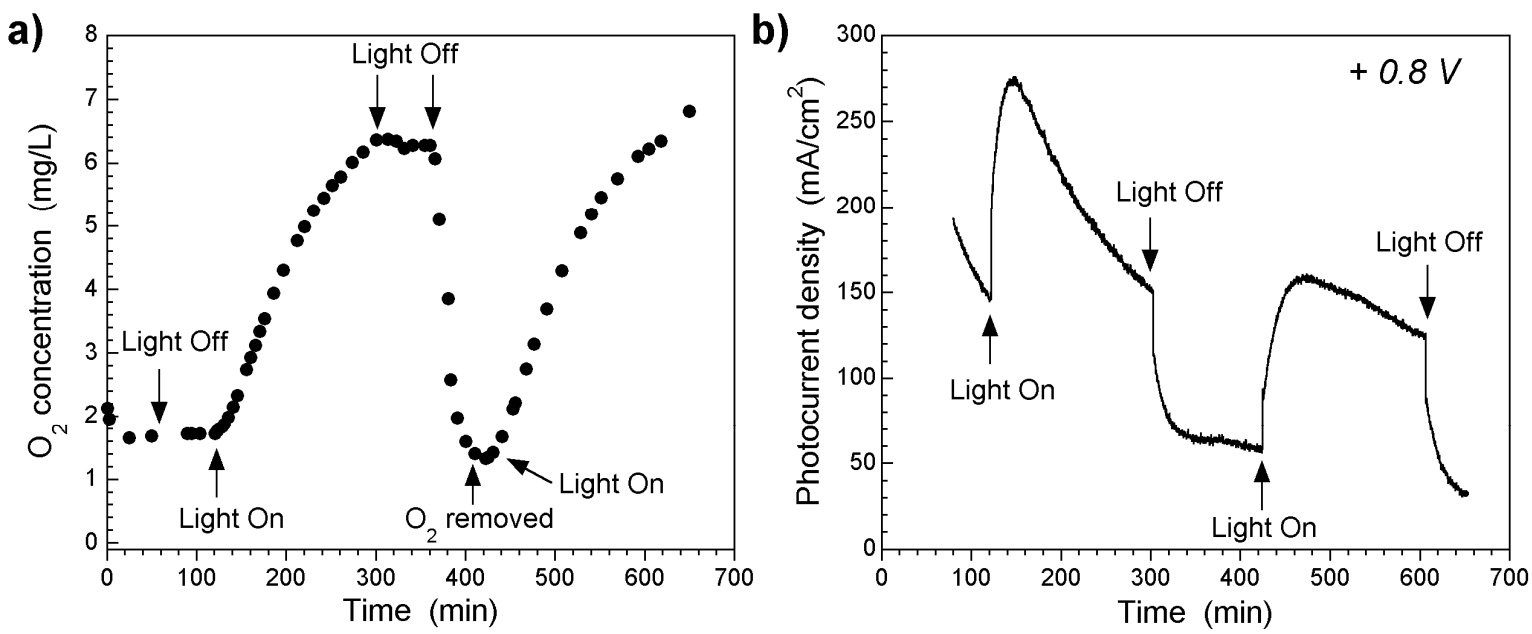

Figure 3. (a) $\mathrm{O}_{2}$ evolution during chronoamperometry run; (b) Chronoamperometric response of the carbon (CONS-I) photoanode upon on/off illumination for long term at $+0.8 \mathrm{~V} \mathrm{vs} \mathrm{Ag} / \mathrm{AgCl}$.

The surface chemistry of the initial (I) and exposed sample (E) was analyzed by XPS. The atomic concentrations of surface elements are provided in Figure 4. Note that the fluoride is introduced in the binder used for the electrode preparation, and that the traces of sodium are due to the adsorbed electrolyte. As seen, the initial sample has a marked oxygen content which remains more or less constant after the PEC run. The sulfur content decreases and a marked increase in the surface concentration of nitrogen is noticed. The content of carbon also visibly decreased, which could be attributed to a mass effect upon oxidation and/or to its release as $\mathrm{CO} / \mathrm{CO}_{2}$. These modifications of the electrode surface chemistry are linked to the consumption of the vacancies (holes) and/or electrons released during water oxidation. 


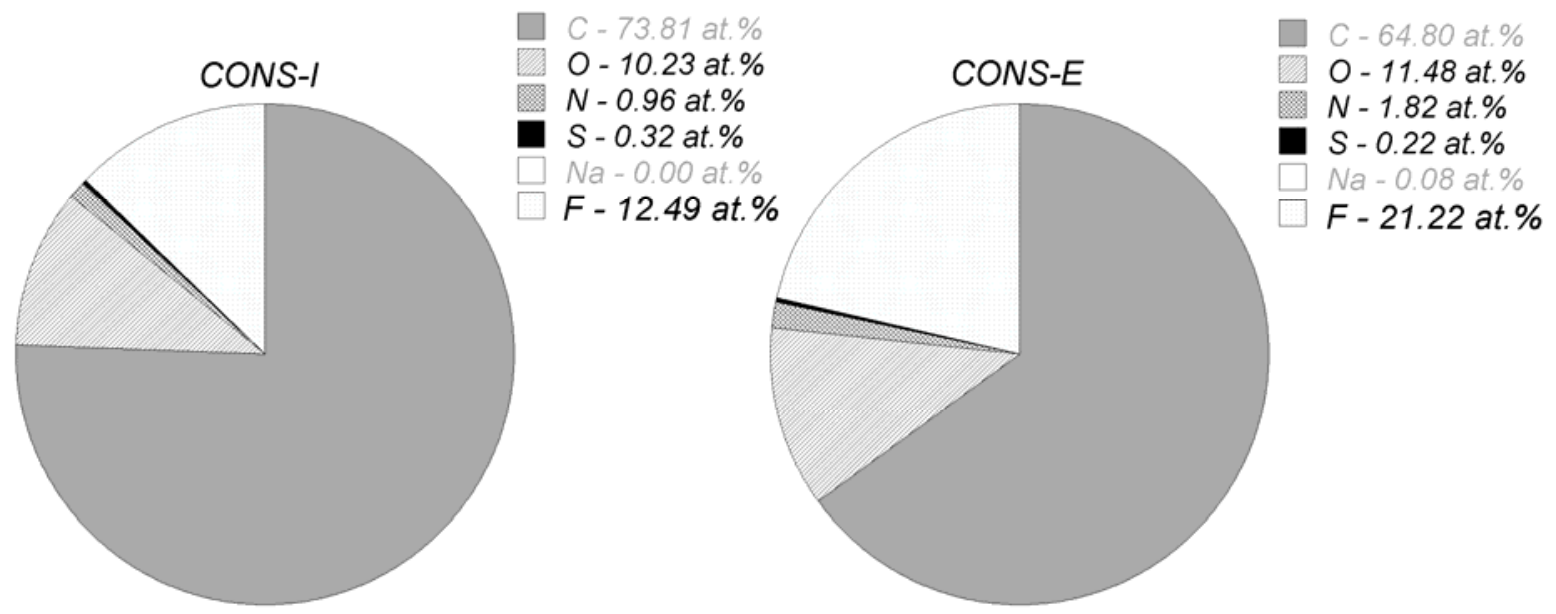

Figure 4. Surface contents of elements (in at. \%).

The deconvoluted $\mathrm{C} 1 s, \mathrm{O} 1 s, \mathrm{~N} 1 s$ and $\mathrm{S} 2 p$ core elements level peaks bring more details on the surface chemistry (Figure 5 and Figure 6). For the initial sample the majority of carbon is in C-C configurations and $38 \%$ in oxidized forms. The results suggest a slight oxidation of carbon during the $\mathrm{CV}$ runs resulting in a new, low binding energy carbon species. A decrease in the amount of sulfur and an increase in nitrogen might be related to the accumulation of additives on the surface and/or changes in the chemical environment seen in the CV curve. In the initial sample nitrogen is mainly in pyrrolic/pyridone configurations, with equal contributions of - $\mathrm{NH}$ and quaternary nitrogen (Figure 5, Table S2 of the Supplementary Information). After the cyclic voltammetry experiment pyridinic nitrogen appears, pyrrolic nitrogen significantly increases and quaternary nitrogen decreases. This suggests that nitrogen species have accepted some of the photogenerated electrons. Conversion of quaternary to pyridinic can explain the appearance of carbon species at low binding energy in the exposed sample (Figure 5 and Figure 6, Table S1 and S2 of the Supplementary Information). For the cycled electrode, the vast majority of sulfur is in the oxidized state, which is a marked difference compared to the initial material. We link these 
changes to the activity of reduced sulfur species in water splitting. Moreover, the oxidation of the electrode by the photogenerated $\mathrm{O}_{2}$, can also take place [25].
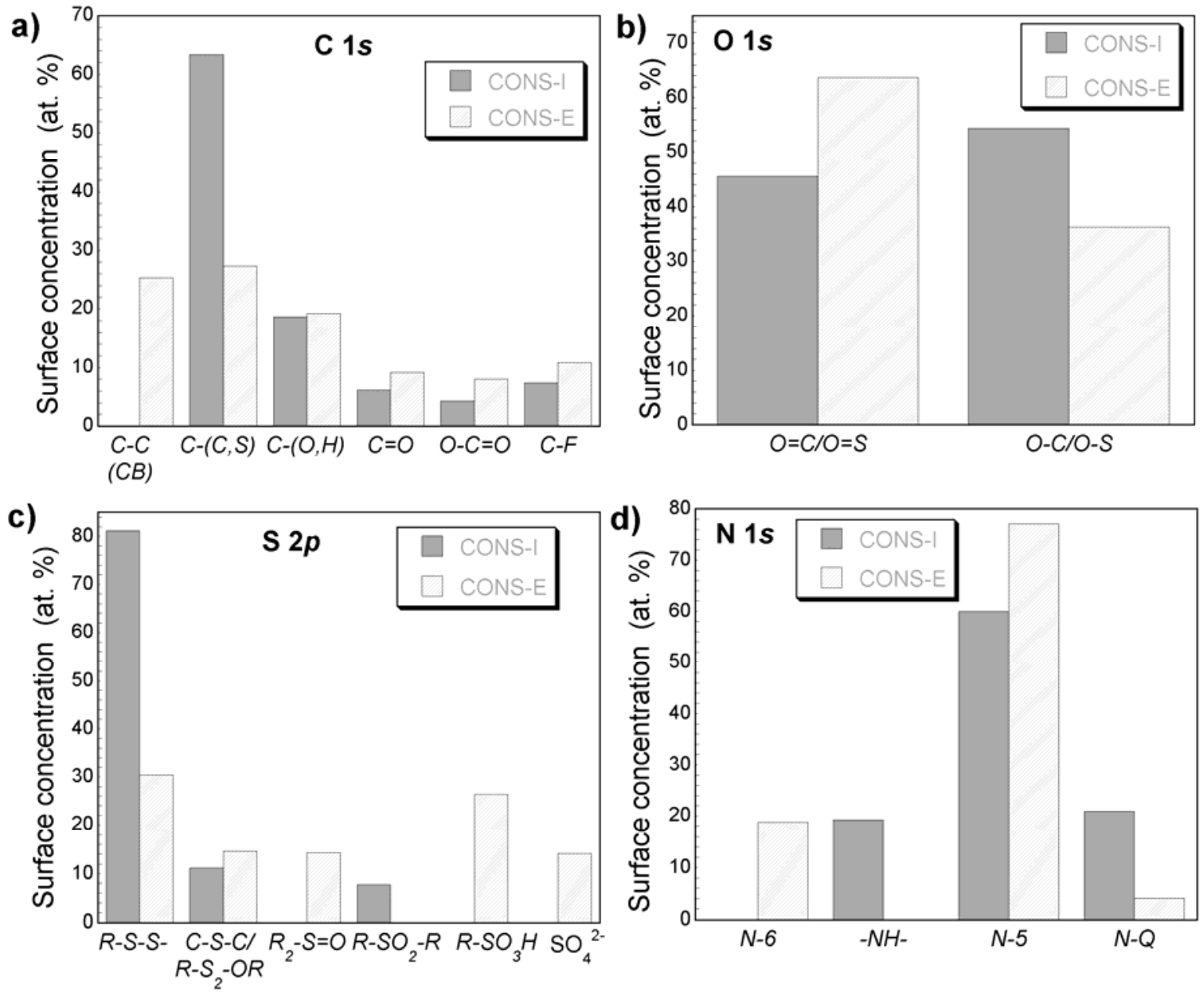

Figure 5. Surface concentration (at. \%) of carbon, oxygen, sulfur and nitrogen species obtained by fitting the $\mathrm{C} 1 s, \mathrm{O} 1 s, \mathrm{~S} 2 p$ and $\mathrm{N} 1 s$ core level peaks of XPS spectra. 

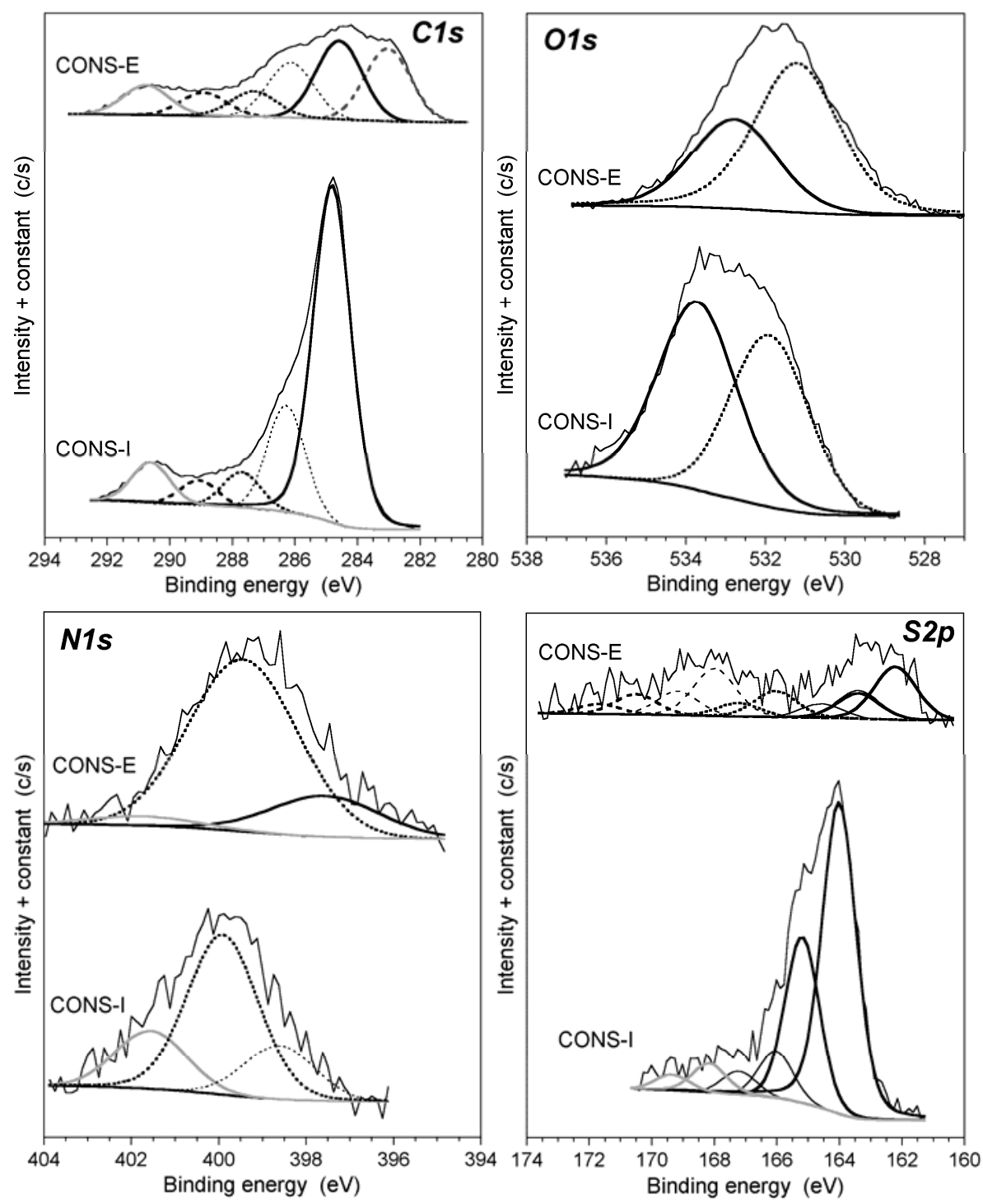

Figure 6. C $1 s, \mathrm{O} 1 s, \mathrm{~N} 1 s$ and S $2 p$ core level spectra for the materials studied.

The resistive shape of the exposed electrode cyclic voltammogram curve evidences the loss of conductivity caused by the changes in the surface chemistry (Figure 5 and 6) and/or an increase in the hydrophobicity. This was confirmed by the changes measured by the water adsorption affinity and impedance spectroscopy in the electrode. Water adsorption values of 17.8 wt. \% and 10.1 wt. \% were measured for CONS-I and CONS-E, respectively. Electrochemical impedance 
spectroscopy measurements further confirmed the unfavorable conductivity of CONS-E. The Nyquist plots (Figure S1 of the Supplementary Information) show semi-circle in both cases, more pronounced in the cycled electrode; since the diameter of the semicircle can be directly related to the charge transfer resistance at the solid/liquid interface, this result confirms the higher polarization resistance of the used electrode to ions diffusion. On the other hand the resistance determined at high frequencies from the Bode plot is similar for both, which is consistent with the electrolyte resistance.

Water alone does not absorb photons with energies high enough to drive its photochemical decomposition. Thus some groups on the nanoporous carbon must act as photosensitizers or chromophores, absorbing certain wavelengths of the sunlight and exciting an electron that would stimulate the photochemical water splitting reactions. Based on the rich surface chemistry of our nanoporous carbon, some of the N-, S-, O- functionalities could account for the light absorption $[14,18]$ and the PEC response measured when exposed to anodic potentials under VL. Sulfone/sulfoxides moieties acting as chromophores have been reported [26], but some other Oand N-containing groups (i.e., azo groups) may also act in a similar way [27]. These moieties would photogenerate the excited electrons that participate in the observed processes and are crucial for the chain of reaction, which must take place in the carbon pore system with adsorbed water molecules. The graphene sheets of the carbon matrix with $\mathrm{S}$ and $\mathrm{N}$ atoms inserted into the aromatic rings located in the proximity of the chromophores would accept the photogenerated electrons, thereby promoting direct $\pi-\pi^{*}$ transitions [4]. Owing to the presence of heteroatoms, the energy difference between the electronic levels is lower than that in pure carbon units [28], facilitating the electron transfer [4]. This leads to the holes/positive charge formation on the chromophore sites that are stabilized by the water molecules yielding $\mathrm{O}_{2}$. The electrons, due to 
water oxidation are transferred through the conductive carbon anode to the counter electrode, recorded as photocurrent. Besides being used for the reduction of protons, electrons could also contribute to the reduction of some groups on the carbon surface, as seen in the changes in the electrochemical response (Figure 2c), XPS results, especially in the reduction of quaternary nitrogen to pyridinic configurations, and in an increase in surface hydrophobicity. The electron transfer efficiency from water to the vacancies of the chromophores, which we consider as a crucial process for water splitting is enhanced by the presence of water confined (adsorbed) in carbon nanopores.

The role of sulfur and nitrogen heteroatoms is supported by the fact that the BAX surface, on which no activity was found, is free of these species (Table 1). Nevertheless, Table 1 indicates that CONS have even more sulfur and nitrogen heteroatoms than CONS-I, which might appear as a contradictory argument.

Table 1. Surface chemical composition (in at. \%) from XPS analysis.

\begin{tabular}{cccccc}
\hline Sample & $\mathrm{C}$ & $\mathrm{O}$ & $\mathrm{N}$ & $\mathrm{S}$ & $\mathrm{P}$ \\
\hline CONS & 87.8 & 8.6 & 1.3 & 1.7 & $\mathrm{ND}$ \\
CONS-I & 81.4 & 16.6 & 1.2 & 0.7 & $\mathrm{ND}$ \\
$\mathrm{ND}-$ not detected & 91.8 & 7.6 & $\mathrm{ND}$ & $\mathrm{ND}$ & 0.6 \\
\hline
\end{tabular}

To further look into importance of the surface features, the porosity should be analyzed. The nitrogen adsorption isotherms, pore size distributions and the summary of the parameters of the pore structure are presented in Figure 7 and Table 2, respectively. As seen CONS can be considered as nonporous carbon whereas CONS-I is a micro/mesoporous material with a marked 
level of microporosity. The predominant pore size is about $0.6 \mathrm{~nm}$ and the volume of small micropores with sizes less than $1 \mathrm{~nm}$, is greater than that of wood-based carbon (BAX). Taking into account that the size of water molecule is $0.3 \mathrm{~nm}$ [29] these pore should be optimal for water adsorption via the strongest dispersive forces. Presence of nitrogen and sulfur in the graphitic layers/walls of these pores can increase the strength of these dispersive interactions. This is owing to the apparent positive charge on carbon atoms in the vicinity of the heteroatoms, as a result of their higher electronegativity than that of nonporous carbon containing $\mathrm{S}$ and $\mathrm{N}$ functional groups. This can further enhance the withdrawing of electrons from oxygen to the vacancies on the chromophores. Moreover, the hydrogen bonding with the surface groups existing in larger pores can also promote the surface wetting and thus increase an accessibility of water to small pores. Even though BAX carbon has a porous nature, it is not active for water splitting owing to the absence of the catalytic sites. The importance of the light active sites containing sulfur and nitrogen for photoluminescence of nanoporous carbons has been analyzed recently [18].
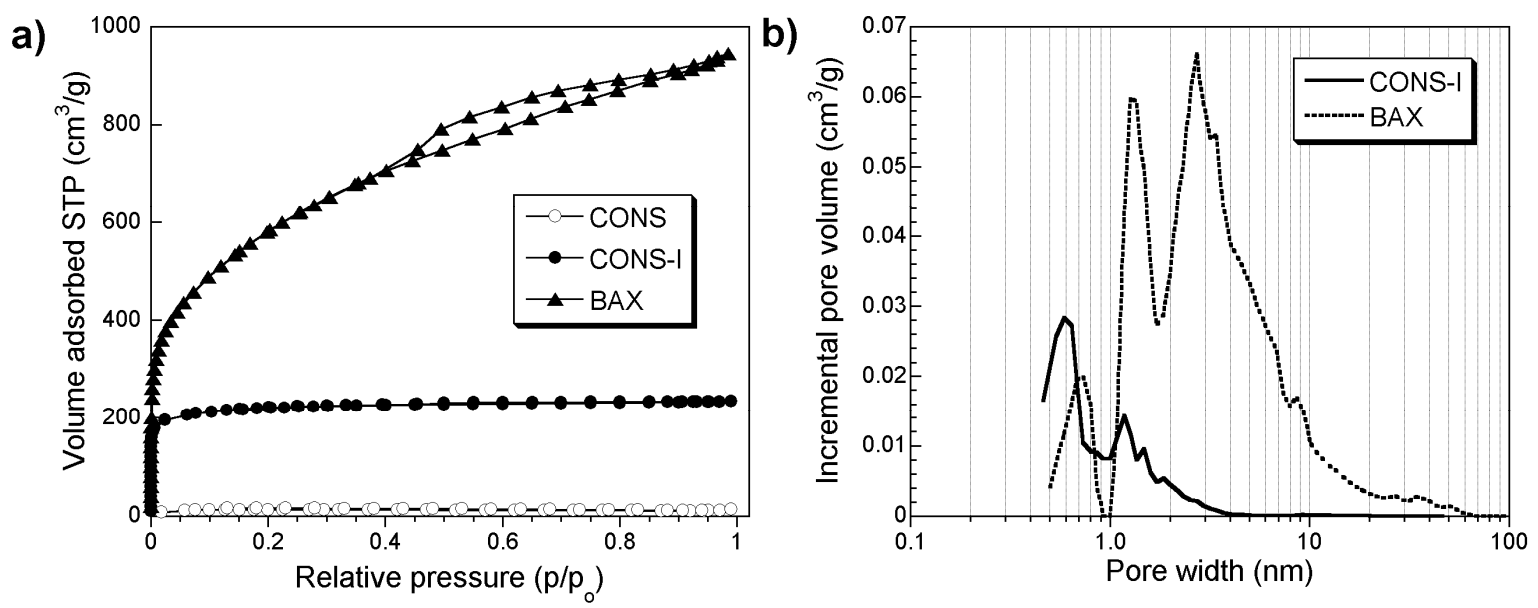

Figure 7. (a) $\mathrm{N}_{2}$ adsorption isotherm at $-196{ }^{\circ} \mathrm{C}$ and (b) pore size distribution of the materials studied. 
Table 2. The parameters of porous structure calculated from nitrogen adsorption measurements, amount of water adsorbed per total pore volumes and the samples' conductivity $(\sigma)$.

\begin{tabular}{lccccc|cc}
\hline Sample & $\begin{array}{c}\mathrm{S}_{\mathrm{BET}} \\
\left(\mathrm{m}^{2} / \mathrm{g}\right)\end{array}$ & $\begin{array}{c}\mathrm{V}_{\mathrm{t}} \\
\left(\mathrm{cm}^{3} / \mathrm{g}\right)\end{array}$ & $\begin{array}{c}\mathrm{V}_{\text {meso }} \\
\left(\mathrm{cm}^{3} / \mathrm{g}\right)\end{array}$ & $\begin{array}{c}\mathrm{V}_{<1 \mathrm{~nm}} \\
\left(\mathrm{~cm}^{3} / \mathrm{g}\right)\end{array}$ & $\begin{array}{c}\mathrm{V}_{\text {mic }}(\mathrm{DFT}) \\
\left(\mathrm{cm}^{3} / \mathrm{g}\right)\end{array}$ & $\begin{array}{c}\mathrm{H}_{2} \mathrm{O} / \mathrm{V}_{\mathrm{t}} \\
\left(\mathrm{mg} / \mathrm{cm}^{3}\right)\end{array}$ & $\begin{array}{c}\sigma \\
(\mathrm{S} / \mathrm{m})\end{array}$ \\
\hline CONS & 38 & 0.022 & 0.021 & 0.000 & 0.001 & -- & 0.5 \\
CONS-I & 727 & 0.363 & 0.103 & 0.184 & 0.260 & 24.4 & 0.6 \\
BAX & 2010 & 1.463 & 0.991 & 0.112 & 0.472 & 29.4 & $4.1 \times 10^{-4}$ \\
\hline
\end{tabular}

The electron transfer on the surface of CONS-I can be analogous to that reported for the photoactive Yellow protein, where 4-hydroxycinnamyl thioester -the chromophore- was identified as responsible for its photoactivity [30]. In our case thioesters are present and conjugated $\mathrm{C}=\mathrm{C}$ bonds in the graphene units easy accept the electrons, which leads to the partial reduction of other surface species. The formed holes on the surface groups accept the electrons from water confined in the nanospace. Besides thioesters, other groups as sulfones could also be active. An increase in quinone moieties after VL exposure supports the similarity of the photoactivity mechanism on the carbon studied to that on Yellow protein.

The fast charge propagation through the carbon matrix is supported by the HRTEM micrographs, which show $\sim 10 \mathrm{~nm}$ domains of a graphitic structure, very unusual for nanoporous carbons (Figure 8a). The presence of these conductive units is also supported by the XRD and Raman analyses (Figure 8c, d). G and D bands on the Raman spectra are clearly visible at $1590 \mathrm{~cm}^{-1}$ and $1360 \mathrm{~cm}^{-1}$, respectively. The narrow $\mathrm{G}$ band indicates the presence of some ordered graphiticlike units in these carbon materials [31]. Further support for superiority of CONS-I is in highest 
DC conductivity. As seen from Table 2 is it three orders of magnitude greater than that for the wood-based (BAX) carbon sample.
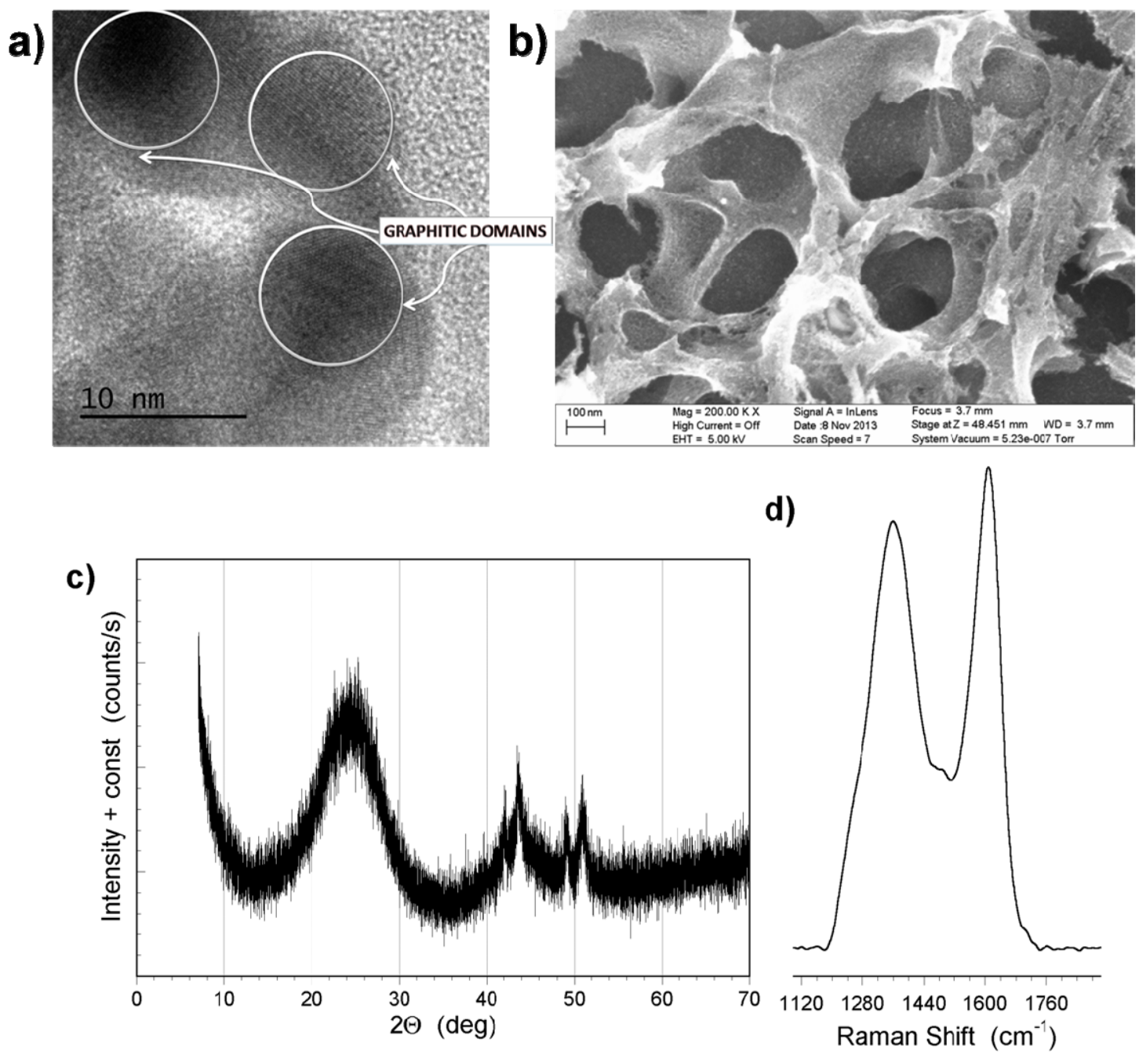

Figure 8. Characterization of the materials studied: a) HRTEM; b) SEM images, respectively; c) XRD pattern; d) Raman spectra.

The optical properties of amorphous carbon materials (photoactivity and photoluminescence) have been discussed in terms of the density of electronic states (DOS) formed by $\sigma$ and $\pi$ bands, which energy spread of states depends upon the $\mathrm{sp}^{2} / \mathrm{sp}^{3}$ content and configuration [14, 32-34]. 
The size and ordering of the $\mathrm{sp}^{2}$ clusters, their population in the carbon matrix and the distortions of $\pi$ states have been suggested as controlling the width of the band gap. Hence, the light absorption features of amorphous carbons are dominated by $\pi-\pi^{*}, \sigma-\sigma^{*}$ and some other transitions involving intermediate states [32-35]. Thus the photoactivity of our carbon for water splitting reactions should not be linked entirely to the presence of chromophores. They are certainly important for water splitting mechanism, as discussed above. Nevertheless, the generation of holes and electrons as a result of band gap alteration can also have some contribution to the observed phenomenon.

\section{Conclusions}

The results presented in this paper show the unique PEC activity of our nanoporous carbon for the OER. Owing to the specificity of the precursor and synthesis conditions, this material surface is rich in "photosensitizers" and conductive graphene units. Light exposure causes the photogeneration of charge carriers on the chromophore-like moieties that leads to the photoelectrochemical oxidation of water at a very low overpotential. The presence of a well developed porosity is essential, and it markedly distinguishes this particular carbon from graphene and on CNT after various modifications. Furthermore, the synthesis method is simple and cost effective. The future challenge is in determining which particular chromophore arrangements are the most important and stable and how to achieve their high distribution and stability on a porous carbon matrix in a controlled way. The results indicate that nanoporous carbons decorated with chromophores can be a source of VL active catalysts mimicking the biological systems. 


\section{Acknowledgements}

This work was partially supported by the Spanish MINECO (grants CTM2011/23378 and CTQ2012-37925-C03-03 and FEDER funds). COA thanks her Salvador de Madariaga Mobility Action (PRX12/00290).

\section{Appendix A. Supplementary data}

Supplementary data associated with this article can be found, in the online version.

\section{REFERENCES}

1. Wang D, Hisatomi T, Takata T, Pan C, Katayama M, Kubota J, et al. Core/shell photocatalyst with spatially separated co-catalysts for efficient reduction and oxidation of water. Angew Chem Int Ed 2013;52:11252-6; Angew Chem 2013;125:11462-6.

2. Maeda K, Lu D, Domen K. Direct water splitting into hydrogen and oxygen under visible light by using modified TaON photocatalysts with $\mathrm{d}^{0}$ electronic configuration. Chem Eur $\mathrm{J}$ 2013;19:498691.

3. Maeda K. Direct splitting of pure water into hydrogen and oxygen using rutile titania powder as a photocatalyst. Chem Commun 2013;49:8404-6.

4. Xie G, Zhang K, Guo B, Liu Q, Fang L, Gong JR. Graphene-based materials for hydrogen generation from light-driven water splitting. Adv Mater 2013;25:3820-39.

5. Kim YK, Park H. How and to what extent do carbon materials catalyze solar hydrogen production from water? Appl Catal B Environ 2012;125:530-7. 
6. $\mathrm{Ng} \mathrm{YH}$, Iwase A, Kudo A, Amal R. Reducing graphene oxide on a visible-light $\mathrm{BiVO}_{4}$ photocatalyst for an enhanced photoelectrochemical water splitting. J Phys Chem Lett 2010;1:2607-12.

7. Wang X, Maeda K, Thomas A, Takanabe K, Xin G, Carlsson JM, et al. A metal-free polymeric photocatalyst for hydrogen production from water under visible light. Nat Mater 2009;8:76-80.

8. Zhao Y, Nakamura R, Kamiya K, Nakanishi S, Hashimoto K. Nitrogendoped carbon nanomaterials as non-metal electrocatalysts for water oxidation. Nat Commun 2013;4:2390-7.

9. Yeh T-F, Teng C-Y, Chen S-J, Teng H. Nitrogen-doped graphene oxide quantum dots as photocatalysts for overall water-splitting under visible light illumination. Adv Mater 2014;26:3297-303.

10. Yang S, Gong Y, Zhang J, Zhan L, Ma L, Fang Z, et al. Exfoliated graphitic carbon nitride nanosheets as efficient catalysts for hydrogen evolution under visible light. Adv Mater $2013 ; 25: 2452-6$.

11. Yeh T-F, Chen S-J, Yeh C-S, Teng H. Tuning the electronic structure of graphite oxide through ammonia treatment for photocatalytic generation of $\mathrm{H}_{2}$ and $\mathrm{O}_{2}$ from water splitting. $\mathrm{J}$ Phys Chem C 2013;117:6516-24.

12. Yeh T-F, Syu J-M, Cheng C, Chang T-H, Teng H. Graphite oxide as a photocatalyst for hydrogen production from water. Adv Funct Mater 2010;20:2255-62.

13. Bandosz TJ, Matos J, Seredych M, Islam MSZ, Alfano R. Photoactivity of S-doped nanoporous activated carbons: A new perspective for harvesting solar energy on carbon-based semiconductors. Appl Catal A: Gen 2012;445-446:159-65. 
14. Velasco LF, Lima JC, Ania CO. Visible-light photochemical activity of nanoporous carbons under monochromatic light. Angew Chem Int Ed 2014;53:4146-8; Angew Chem $2014 ; 126: 4230-2$

15. Seredych M, Bandosz TJ. Effect of the graphene phase presence in nanoporous S-doped carbon on photoactivity in UV and visible light. Appl Catal B Environ 2014;147:842-50.

16. Seredych M, Bandosz TJ. S-doped micro/mesoporous carbon/graphene composites as efficient supercapacitors in alkaline media. J Mater Chem A 2013;1:11717-27.

17. Velasco LF, Fonseca IM, Parra JB, Lima JC, Ania CO. Photochemical behaviour of activated carbons under UV irradiation. Carbon 2012;50:249-58.

18. Bandosz TJ, Rodriguez-Castellon E, Montenegro JM, Seredych M. Photoluminescence of nanoporous carbons: Opening a new application route for old materials. Carbon 2014;77:651-9.

19. Hines D, Bagreev A, Bandosz TJ. Surface properties of porous carbon obtained from polystyrene sulfonic acid-based organic salts. Langmuir 2004;20:3388-97.

20. Lastoskie CM, Gubbins KE, Quirke N. Pore size distribution analysis of microporous carbons: A density functional theory approach. J Phys Chem 1993;97:4786-96.

21. Olivier JP. Modeling physical adsorption on porous and nonporous solids using density functional theory. J Porous Mater 1995;2:9-17.

22. Pandolfo A G, Hollenkamp AF. Carbon properties and their role in supercapacitors. J Power Sour 2006;157:11-27.

23. Frackowiak E, Beguin F. Carbon materials for the electrochemical storage of energy in capacitors. Carbon 2001;39:937-50. 
24. Wang WS, Wang $\mathrm{DH}, \mathrm{Qu}$ WG, $\mathrm{Lu} \mathrm{LQ}, \mathrm{Xu} \mathrm{AW}$. Large ultrathin anatase $\mathrm{TiO}_{2}$ nanosheets with exposed $\{001\}$ facets on graphene for enhanced visible light photocatalytic activity. J Phys Chem C 2012;116:19893-901.

25. Henning GR. Electron microscopy of reactivity changes near lattice defects in graphite. In: Walker PL, editor. Chemistry and physics of carbon, vol 2, New York; Marcel Dekker; 1966 p. $1-49$.

26. Beecher JE, Durst T, Fréchet JMJ, Godt A, Pangborn A, Robello DR, et al. New chromophores containing sulfonamide, sulfonate, or sulfoximide groups for second harmonic generation. Adv Mater 1993;5:632-4.

27. Jin G, Zhang Y, Cheng W. Poly(p-aminobenzene sulfonic acid)-modified glassy carbon electrode for simultaneous detection of dopamine and ascorbic acid. Sens Act B 2005;107:52834.

28. StrelkoVV, Kutz VS, Thrower PA. On the mechanism of possible influence of heteroatoms of nitrogen, boron and phosphorus in a carbon matrix on the catalytic activity of carbons in electron transfer reactions. Carbon 2000;38:1499-524.

29. Brennan JK, Bandosz TJ, Thomson KT, Gubbins KE. Water in porous carbons. Colloids Surf A: Physicochem Eng Asp 2001;187-188:539-68.

30. Baca M, Borgstahl GE, Boissinot M, Burke PM, Williams DR, Slater KA, et al. Complete chemical structure of photoactive yellow protein: Novel thioester-linked 4-hydroxycinnamyl chromophore and photocycle chemistry. Biochemistry 1994;33:14369-77.

31. Huh SH. Thermal reduction of graphene oxide. In: Mikhailov S, editor. Physics and applications of graphene - experiments, InTech; 2011 p. 73-90. 
32. Robertson J. Recombination and photoluminescence mechanism in hydrogenated amorphous carbon. Phys Rev B 1996;53:16302-5.

33. Robertson J. Mechanical properties and coordinations of amorphous carbons. J Phys Rev Lett 1992;68:220-3.

34. Theye M-L, Paret V. Spatial organization of the $\mathrm{sp}^{2}$-hybridized carbon atoms and electronic density of states of hydrogenated amorphous carbon films. Carbon 2002;40:1153-66.

35. Robertson J, O’Reilly EP. Electronic and atomic structure of amorphous carbon. Phys Rev B 1987;35:2946-57. 


\section{CAPTIONS TO THE TABLES}

Table 1. Content of elements on the surface (in at. \% from XPS analysis).

Table 2. The parameters of porous structure calculated from nitrogen adsorption measurements, amount of water adsorbed per total pore volumes and the samples' conductivity $(\sigma)$.

\section{CAPTIONS TO THE FIGURES}

Figure 1. Chemical formula of the carbon precursor, Poly(4-ammonium styrene-sulfonic acid) polymer.

Figure 2. (a) photocurrent vs bias potential of the photoanodes; (b) chronoamperometric response of sample CONS-I upon on/off illumination at $0.8 \mathrm{~V}$ vs $\mathrm{Ag} / \mathrm{AgCl}$; c) $\mathrm{CV}$ curves before and after VL exposure.

Figure 3. (a) $\mathrm{O}_{2}$ evolution during chronoamperometry run; (b) Chronoamperometric response of the carbon (CONS-I) photoanode upon on/off illumination for long term at $+0.8 \mathrm{~V}$ vs $\mathrm{Ag} / \mathrm{AgCl}$. Figure 4. Surface contents of elements (in at. \%).

Figure 5. Surface concentration (at. \%) of carbon, oxygen, sulfur and nitrogen species obtained by fitting the C $1 s, \mathrm{O} 1 s, \mathrm{~S} 2 p$ and $\mathrm{N} 1 s$ core level peaks of XPS spectra.

Figure 6. C $1 s, \mathrm{O} 1 s, \mathrm{~N} 1 s$ and $\mathrm{S} 2 p$ core level spectra of XPS spectra for the materials studied. Figure 7. (a) $\mathrm{N}_{2}$ adsorption isotherm at $-196{ }^{\circ} \mathrm{C}$ and (b) pore size distribution for the materials studied.

Figure 8. Characterization of the materials studied: a) HRTEM; b) SEM images, respectively; c) XRD pattern; d) Raman spectra. 


\section{ELECTRONIC SUPPLEMENTARY INFORMATION}

\section{Visible Light Driven Photoelectrochemical Water Splitting on Metal Free Nanoporous Carbon Promoted by Chromophoric Functional Groups}

Conchi O. Ania, ${ }^{a}$ Mykola Seredych, ${ }^{\mathrm{b}}$ Enrique Rodríguez-Castellón, ${ }^{\mathrm{c}}$ and Teresa J. Bandosz ${ }^{\mathrm{b}}$

${ }^{a}$ Department of Chemical Processes in Energy and Environment, Instituto Nacional del Carbón (INCAR, CSIC), C/ Francisco Pintado Fe 26, Oviedo 33011, Spain

${ }^{b}$ Department of Chemistry and CUNY Energy Institute, The City College of New York, 160 Convent Ave, New York, NY 10031, United States

cDepartamento de Química Inorgánica, Facultad de Ciencias, Universidad de Málaga, 29071 Málaga, Spain

${ }^{*}$ Corresponding author. Tel: +1212650 6017; Fax: +1212650 6107. E-mail address: tbandosz@ccny.cuny.edu (T.J. Bandosz) 
Table S1. Concentration (atomic \%) of elements detected on the surface of the initial and exposed polymer-derived carbons.

\begin{tabular}{lcccccc}
\hline Sample & $\mathrm{C}$ & $\mathrm{O}$ & $\mathrm{N}$ & $\mathrm{S}$ & $\mathrm{Na}$ & $\mathrm{F}$ \\
\hline CONS-I & 73.81 & 10.23 & 0.96 & 0.32 & --- & 12.49 \\
CONS-E & 64.80 & 11.48 & 1.82 & 0.22 & 0.08 & 21.22 \\
\hline
\end{tabular}

Table S2. Surface concentration (in \%) of carbon, oxygen, sulfur and nitrogen species obtained by fitting the $\mathrm{C} 1 s, \mathrm{O} 1 s, \mathrm{~N} 1 s$ and $\mathrm{S} 2 p$ core level peaks of XPS spectra.

\begin{tabular}{|c|c|c|}
\hline & CONS-I & CONS-E \\
\hline C-C (from amorphous carbon black $-283.0 \mathrm{eV}$ ) & --- & 25.28 \\
\hline $\mathrm{C}-(\mathrm{C}, \mathrm{S}, \mathrm{N})$ (graphitic carbon - $284.6 \mathrm{eV})$ & 63.42 & 27.36 \\
\hline C-O, C-N, C-H (phenolic, alcoholic, etheric - $286.1 \mathrm{eV}$ ) & 18.64 & 19.20 \\
\hline $\mathrm{C}=\mathrm{O}($ carbonyl or quinone $-287.3 \mathrm{eV})$ & 6.20 & 9.20 \\
\hline $\mathrm{O}-\mathrm{C}=\mathrm{O}($ carboxyl or ester $-288.9 \mathrm{eV})$ & 4.34 & 8.08 \\
\hline $\mathrm{C}-\mathrm{F}(290.7 \mathrm{eV})$ & 7.40 & 10.88 \\
\hline $\mathrm{O}=\mathrm{C} / \mathrm{O}=\mathrm{S}$ (in carboxyl/carbonyl or sulfoxides $/$ sulfones $-531.7 \mathrm{eV}$ ) & 45.62 & 63.71 \\
\hline $\mathrm{O}-\mathrm{C} / \mathrm{O}-\mathrm{S}$ (in phenol/epoxy or thioethers/sulfonic $-533.7 \mathrm{eV}$ ) & 54.38 & 36.29 \\
\hline R-S-S- (in bisulfides configuration - $163.9 \mathrm{eV}$ ) & 81.13 & 30.47 \\
\hline $\mathrm{C}-\mathrm{S}-\mathrm{C} / \mathrm{R}-\mathrm{S}_{2}-\mathrm{OR}$ (in sulfides and thioethers $-165.6 \mathrm{eV}$ ) & 11.20 & 14.60 \\
\hline $\mathrm{R}_{2}-\mathrm{S}=\mathrm{O}$ (in sulfoxides $-167.1 \mathrm{eV}$ ) & --- & 14.31 \\
\hline $\mathrm{R}-\mathrm{SO}_{2}-\mathrm{R}$ (in sulfones $-168.0 \mathrm{eV}$ ) & 7.77 & --- \\
\hline $\mathrm{R}-\mathrm{SO}_{3} \mathrm{H}$ (in sulfonic acids $-169.4 \mathrm{eV}$ ) & --- & 26.39 \\
\hline $\mathrm{SO}_{4}{ }^{2-}($ sulfate $-168.6 \mathrm{eV})$ & --- & 14.14 \\
\hline N-6 (in pyridinic $-397.9 \mathrm{eV}$ ) & --- & 18.79 \\
\hline$-\mathrm{N}-\mathrm{H}-($ in amines $-398.9 \mathrm{eV})$ & 19.21 & --- \\
\hline N-5 (in pyrrolic/pyridone and azo nitrogen $-400.4 \mathrm{eV}$ ) & 59.98 & 77.07 \\
\hline $\mathrm{N}-\mathrm{Q}$ (in quaternary $-401.8 \mathrm{eV}$ ) & 20.88 & 4.14 \\
\hline
\end{tabular}



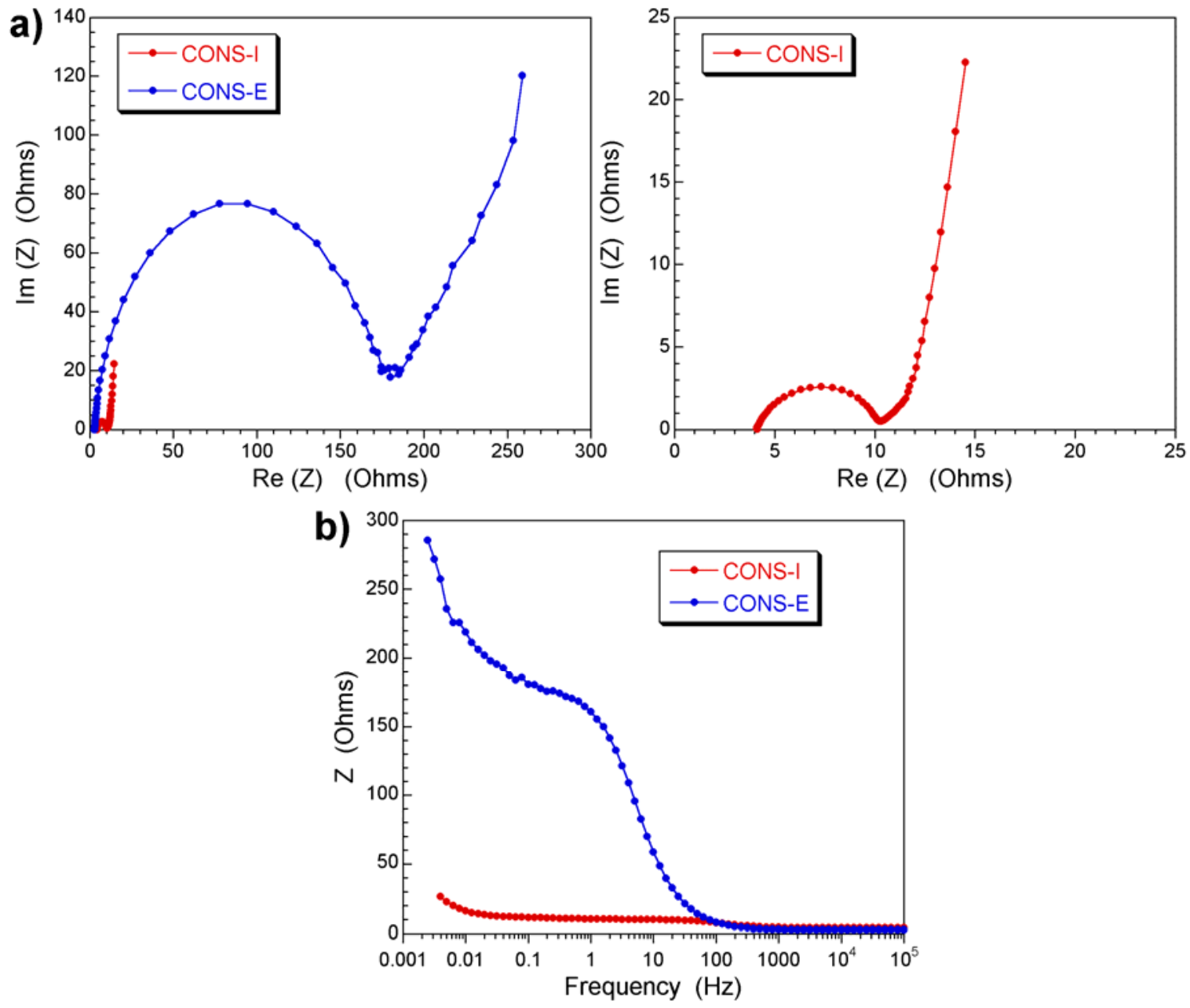

Figure S1. a) Nyquist and b) Bode plots for the polymer-derived carbon before (CONS-I) and after water splitting (CONS-E). 
a)

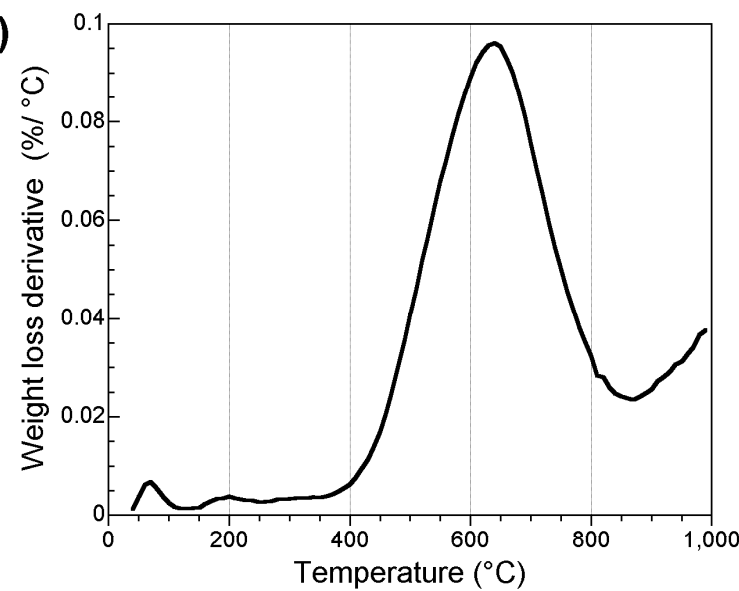

c)

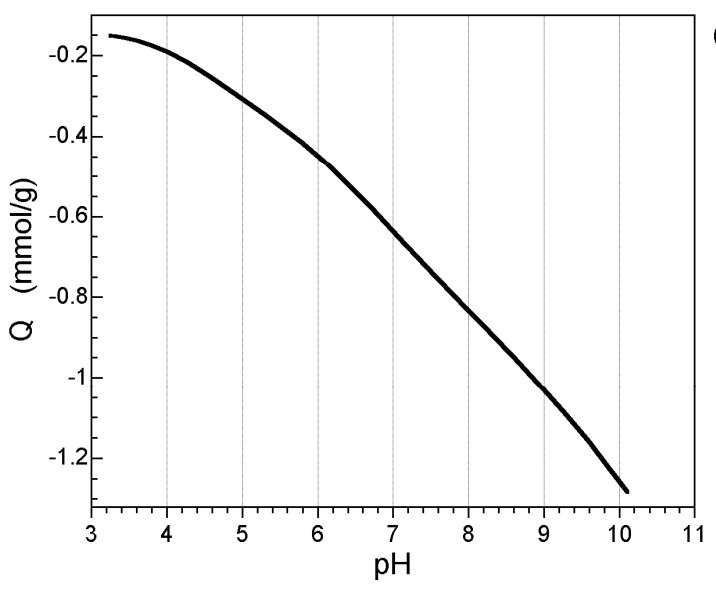

b)

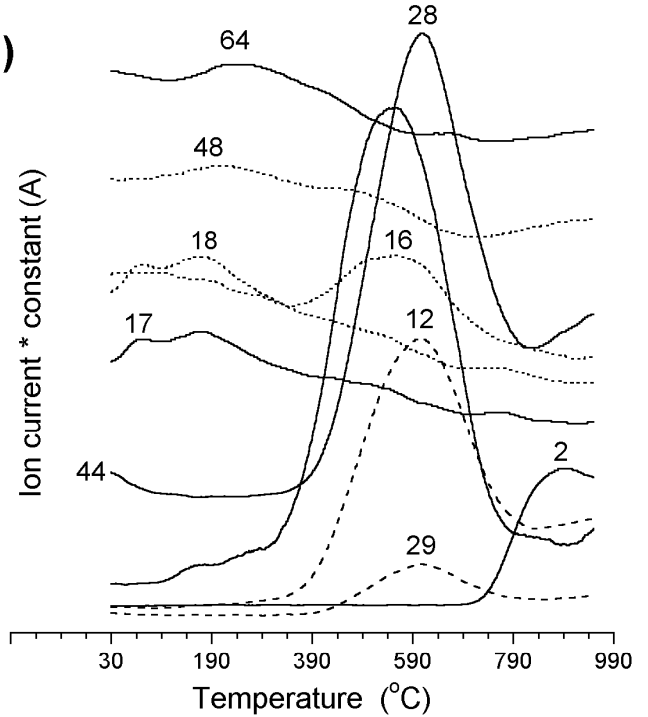

d)

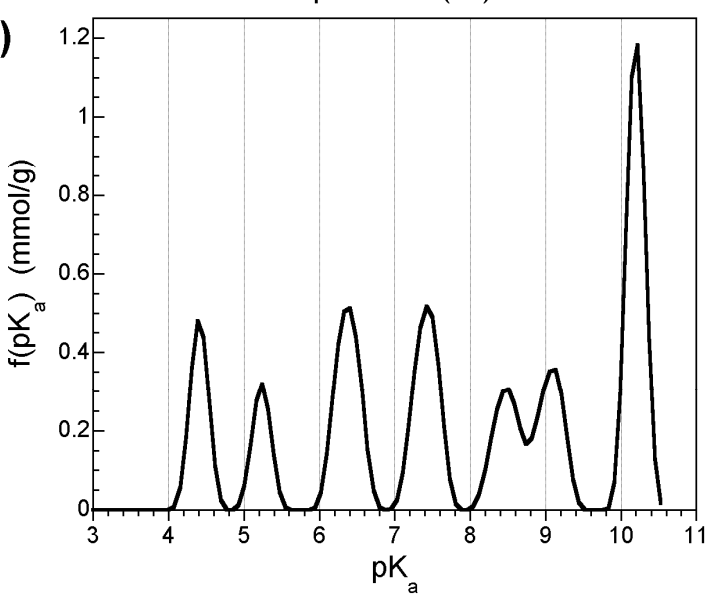

Figure S2. Surface characterization: a) DTG curves in helium; b) mass-spectroscopy patterns (multiplication factor: MW-2 / 8; MW-12 x 20; MW-16 x 7; MW-17 x 3; MW-18 x 1; MW-28 x 1; MW-29 x 10; MW-44 x 5; MW-48 x 500; MW-64 x 500); c) proton binding curve and d) $\mathrm{pK}_{\mathrm{a}}$ distribution. 

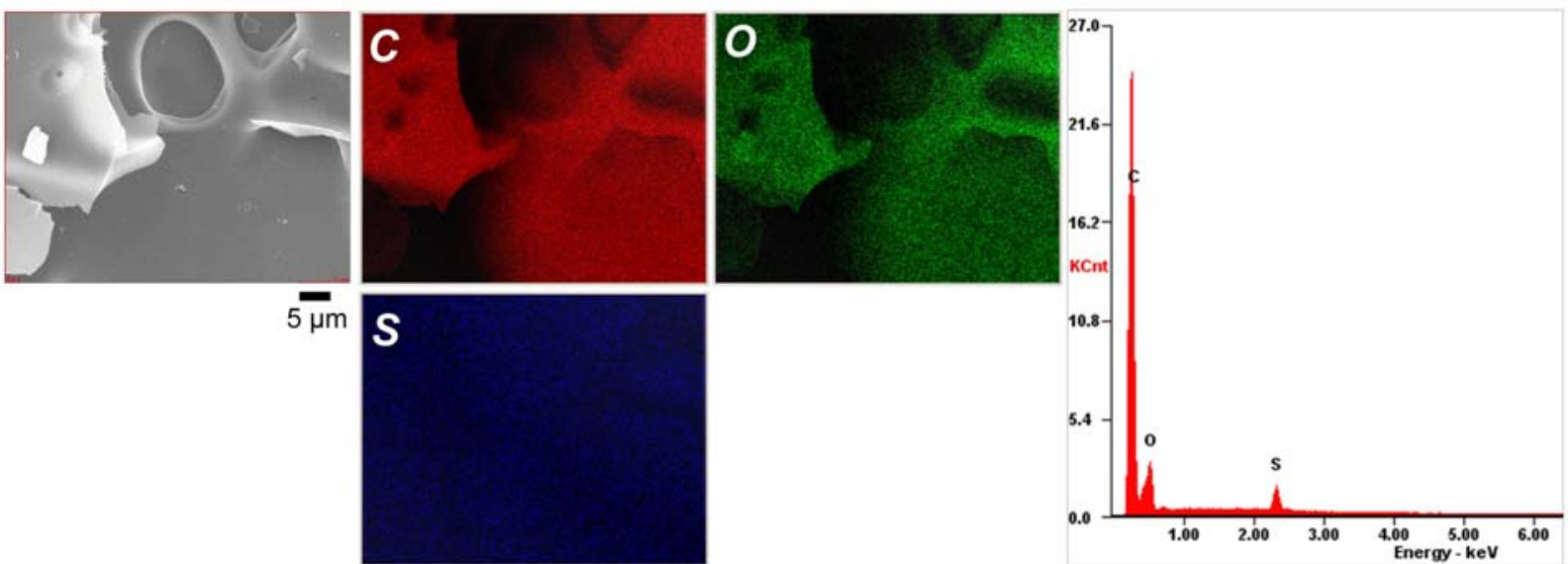

Figure S3. EDX map showing the distribution of heteroatoms on the nanoporous carbon. 